\title{
Interocular transfer of a brightness and of a pattern discrimination in albino and pigmented guinea pigs*
}

\author{
KATHLEEN A. B. LYNCH and CHARLES L. SHERIDAN \\ University of Missouri, Kansas City, Mo. 641 10 and \\ Veterans Administration Hospital, Kansas City, Mo. 64128
}

Interocular transfer of a brightness and of a pattern discrimination was measured in albino and pigmented guinea pigs. Substantial amounts of transfer occurred regardless of problem type or pigmentation, and neither problem type nor pigmentation had a reliable influence on interocular transfer. Transfer, though considerable, was incomplete.

Petre \& Sheridan (1966) measured interocular transfer in guinea pigs from the first day postpartum to about 14 days of age. They found that transfer was incomplete in young animals, but the median percentage transfer was $100 \%$ in older ones. Levinson \& Sheridan (1967) showed that adult guinea pigs readily learn an original and a reversal discrimination mediated by opposite eyes. The latter finding seems inconsistent with Petre and Sheridan's report of complete interocular transfer in relatively mature guinea pigs. The present study was intended to be a rather exhaustive analysis of interocular transfer in adult guinea pigs. Two main variables of interest were manipulated. Both brightness and pattern discrimination were used, since it is well known that these two types of discrimination commonly differ in the degree to which they transfer (cf. Meikle \& Sechzer, 1960, with Sheridan, 1965). Albino and pigmented Ss were employed, since pigmentation of the eye is related to degree of interocular transfer in rats (Sheridan, 1965) and might also be so related in guinea pigs.

\section{SUBJECTS}

Twenty albino and 20 pigmented guinea pigs were assigned to 10 groups of four Ss each. Each group contained animals of like color and sex except for two groups: one group contained two pigmented and two albino males and the other group contained two pigmented and two albino females. All animals were young adults (approximately $700-900 \mathrm{~g}$ ) caged in groups of four and maintained ad lib on food and water.

\section{APPARATUS}

Discriminanda were presented to $S s$ in a shock-avoidance apparatus similar to that designed by Thompson \& Bryant (1955). This apparatus consists of a startbox and a runway with independently electrifiable grids and a wooden-floored goalbox that $\mathrm{Ss}$ entered through one of two $4 \times 4$ in.

*This research was supported in part by Veterans Administration 8200 (Research) funds and in part by Grant 8 R01F.Y00586-0451 to Charles L. Sheridan. doorways equipped on the goalbox side with small wingnut locks. These permitted locking of "wrong-choice" doors. Discriminanda were placed on the doors. Four inches in front of each doorway there were separate entryway grids constructed to permit independent presentation of motivational shock. Clear Plexiglas covered the top of the apparatus. Each of the choice points, the startbox, and the runway could be electrified by a pulsed ( $1 / 2 \mathrm{sec}$ on, $1 / 2 \mathrm{sec}$ off) current supplied by Lehigh Valley Electronics Model No. 1311 constant wattage shocker. When electrified, the entryway grids presented shock at the same parameters, except that the shock was continuous, not pulsed. A fixed intensity was found to motivate all Ss except during early training trials when minor individual adjustments were made; the fixed intensity is estimated within $\pm 5.0 \%$ of $200 \mathrm{~mW}$.

\section{PROCEDURE}

Pretraining was carried out on 5 successive days. On Day 1 the animals were introduced to the discrimination apparatus and allowed to explore inside it for $1 \mathrm{~h}$. On Day 2 a 30-min exploratory period was permitted. On Day $3 \mathrm{Ss}$ were introduced to testing procedures.

Immediately upon placement in the startbox, the guillotine door that divided the startbox from the runway was lifted and a $500-\mathrm{Hz}$ tone was sounded for $10 \mathrm{sec}$. This tone was followed by $30 \mathrm{sec}$ electrification of the startbox. The sliding door was lowered when $S$ moved out of the startbox. S was then allowed $10 \mathrm{sec}$ in the runway before the warning tone again sounded. Then grid shock remained on for $30 \mathrm{sec}$ or until $\mathrm{S}$ entered the goalbox. In this way the behavior was shaped toward the entryways and the goalbox. A first precriterion consisted of each S's making five runs without shock. On Day 4 the procedure was the same, except that gray stimulus doors partly covered the runway exits. A criterion of five unshocked runs was again used.
Discrimination training was begun on Day 6. Discriminanda and eyes to be occluded were assigned in a counterbalanced order; also, running order of Ss within each squad was randomized. Occluders were similar to those used in previous experiments on rats (see, for example, Sheridan, 1965; Sheridan \& Shrout, 1965). They were pressed out of black opaque vinyl acrylic with a ball-bearing mold, then trimmed to hemispheric shape. Occluders were constructed in a range of sizes so that a given guinea pig could be fitted with an occluder that would fit the eye to its base.

Next, the stimulus doors were placed in position, and the door with the incorrect stimulus was locked, with the floor grid in front of it electrified. The incorrect stimulus door was aiternated in accordance with a Gellerman (1933) series. Olfactory cues were masked by periodically wiping both discriminandum doors with a cloth that had guinea pig fur and urine on it.

A regimen of 25 trials, at approximately the same time each day, was maintained until a criterion of 18 correct out of 20 total trials was reached. When this $18 / 20$ criterion was reached, an additional "stability" criterion of nine or more correct responses out of 10 trials was imposed. Upon successful completion of this additional criterion, the occluder was removed and immediately placed on the opposite eye. At this point the animal was given 10 shock-free trials in a test for "transfer" (interocular test). Immediately after this test for transfer, occluders were placed on both eyes and the animals were tested for 10 additional shock-free trials. Following the binocular-occlusion phase, the original eye alone was again occluded and shock was reinstated for 10 more trials (original-eye retention test). On the next day, training (with the opposite eye occluded) began and continued at 25 trials per day until the $18 / 20$ criterial performance was reached. A maximum of 500 trials was allowed.

\section{DOOR CONTROLS}

Stimulus cards for the pattern discrimination consisted of 1/2-in. alternating black and white, horizontal or vertical stripes. For the pattern problems the door through which $\mathrm{S}$ entered in order to avoid or escape shock displayed vertical stripes. In the case of the black-white problem, the shock-free door was white. All doors were backed with a strip of foam rubber to reduce noise when knocked down by $S$. Door reversal and random lighting of stimulus cards was used to control for side and corner sampling and for flux cues. Door surfaces were illuminated by a $10-\mathrm{W}$ bulb located immediatcly above the choice point. Stimulus intensity was measured by a 
Table 1

First- and Second-Eye Trials to Criterion and Percentage Savings on Second-Eye Acquisition

\begin{tabular}{|c|c|c|c|c|c|c|}
\hline & \multicolumn{3}{|c|}{ Albino } & \multicolumn{3}{|c|}{ Pigmented } \\
\hline \multirow[t]{2}{*}{. } & \multicolumn{2}{|c|}{ Trials } & \multirow{2}{*}{$\begin{array}{l}\text { Percent } \\
\text { Savings }\end{array}$} & \multicolumn{2}{|c|}{ Trials } & \multirow{2}{*}{$\begin{array}{l}\text { Percent } \\
\text { Savings }\end{array}$} \\
\hline & First & Second & & First & Second & \\
\hline & \multicolumn{6}{|c|}{ Brightness Discrimination } \\
\hline & 345 & 0 & 100.0 & 150 & 95 & 26.7 \\
\hline & 335 & 105 & 68.6 & 205 & 95 & 53.7 \\
\hline & 222 & 250 & -11.4 & 190 & 50 & 73.7 \\
\hline & 365 & 55 & 84.9 & 232 & 95 & 59.1 \\
\hline & 195 & 50 & 74.4 & 280 & 65 & 76.8 \\
\hline & 191 & 0 & 100.0 & 253 & 47 & 81.4 \\
\hline & & & & 195 & 70 & 64.1 \\
\hline \multirow[t]{13}{*}{ Median } & 278.5 & 52.5 & 92.1 & 205 & 70 & 64.1 \\
\hline & \multicolumn{6}{|c|}{ Pattern Discrimination } \\
\hline & 81 & 0 & 100.0 & 200 & 0 & 100.0 \\
\hline & 166 & 0 & $100.0^{-}$ & 126 & 3 & 97.6 \\
\hline & 370 & 180 & 51.4 & 221 & 125 & 43.5 \\
\hline & -172 & 0 & 100.0 & 250 & 125 & 50.0 \\
\hline & 345 & 100 & 65.5 & 215 & 170 & 20.9 \\
\hline & 325 & 225 & 36.9 & 420 & 0 & 100.0 \\
\hline & 270 & 90 & 66.7 & 190 & 0 & 100.0 \\
\hline & 150 & 0 & 100.0 & 132 & 0 & 100.0 \\
\hline & 245 & 0 & 100.0 & 143 & 0 & 100.0 \\
\hline & 227 & 0 & 100.0 & 230 & 52 & 77.3 \\
\hline & 88 & 30 & 64.7 & 115 & 50 & 56.5 \\
\hline Median & 227 & 0 & 100.0 & 200 & 0 & 97.6 \\
\hline
\end{tabular}

Table 2

Percentage of Errors on Interocular Test and Original-Eye Retention Test

\begin{tabular}{|c|c|c|c|}
\hline \multicolumn{2}{|c|}{ Albino } & \multicolumn{2}{|c|}{ Pigmented } \\
\hline $\begin{array}{c}\text { Interocular } \\
\text { Test }\end{array}$ & $\begin{array}{c}\text { Original-Eye } \\
\text { Retention }\end{array}$ & $\begin{array}{c}\text { Interocular } \\
\text { Test }\end{array}$ & $\begin{array}{l}\text { Original-Eye } \\
\text { Retention }\end{array}$ \\
\hline
\end{tabular}

Gossen Luna Six light meter; $35 \mathrm{fc}$ registered without random illumination and $60 \mathrm{fc}$ with random illumination. Illumination in front of all doors was found to be equal within the sensitivity limits of the meter.

\section{RESULTS}

Five Ss died before completion of interocular testing; analyses are based on data obtained from the remaining $35 \mathrm{Ss}$. Acquisition scores from the deleted Ss varied over a wide range and did not appear to be different from those of surviving Ss.

Table 1 shows first- and second-eye trials to criterion and also gives the percentage of savings during second-eye acquisition. For both types of discrimination there was heavy overlap of the albino and pigmented groups with respect to both acquisition measures and the savings measure. It was clear from inspection of the data that pigmentation did not exert a reliable effect on acquisition or interocular transfer in the guinea pig $\mathrm{Ss}$ of this experiment.

Since the median percentage savings for pigmented Ss learning the brightness discrimination was substantially lower than the median percentage for the pattern problem (64.1 vs 97.6), the statistical reliability of the difference was evaluated. A Mann-Whitney $U$ test indicated that the difference was not reliable at the .05 level $\left(U=25, \quad n_{1}=7, \quad n_{2}=11, \quad p>.10\right)$. Amounts of transfer in general did not differ as a function of problem type.

Table 2 shows the percentage of errors made during the interocular test trials and the subsequent original-eye retention test. Once again, it was clear by inspection of the data that the pigmentation had no significant effect on any of the measures. It was also clear that scores from the two types of discrimination overlapped heavily.

By comparing the original-eye retention scores with interocular test scores, the completeness of interocular transfer could be assessed. Since the original-eye retention test was given after the interocular test and after the binocular occlusion test, both of which offered opportunity for loss of baseline performance, this measure provided a conservative estimate of interocular decrement. Still, a sign test revealed that significantly fewer errors were made on the original-eye retention test than on the interocular test for the brightness $(p=.02)$ and for the pattern $(\mathrm{p}<.001)$ discriminations (two-tailed $\mathrm{ps}$ ).

Results of the binocular occlusion test depended on whether or not Ss were pigmented. Fifteen of the 18 pigmented $S s$ made fewer than five errors during the 10-trial test (median $=4$ errors, $\bar{X}=3.7$ errors). A sign test showed that pigmented Ss performed at significantly better than the 50\% level $(\mathrm{p}=.001)$. Albino Ss, on the other hand, performed essentially at chance levels (median $=5$ errors, $\bar{X}=5.1$ errors). Presumably this means that the present measures tended to overestimate interocular transfer in pigmented Ss.

\section{DISCUSSION}

The present findings are in essential agreement with those of Petre \& Sheridan (1966) on two issues. First, they reported that the pigmentation-related variations in interocular transfer that have been observed in rats do not occur in guinea pigs. Second, they reported a median figure of $100 \%$ interocular transfer of a horizontal-vertical discrimination in their mature guinea pigs. The guinea pigs of the present study were run on the same type of discrimination, and, for the pooled albino and pigmented $S s$, the median percentage of interocular transfer was 98.8. Petre \& Sheridan (1966) did not report individual data for their 14- to 37-day-old ("mature") Ss. There were five such Ss, three with $100 \%$ transfer, one with $98 \%$ transfer, and one with $80 \%$ transfer. These scores could easily have come from the $S$ s in the experiment reported here. Furthermore, Petre \& Sheridan (1966) point out that in their 3-day-old group, "... two Ss had almost no savings and the other two showed perfect transfer." This suggests the possibility that Ss in their 3-day-old group and in their 14- to 37-day-old group behaved essentially as $\mathrm{Ss}$ in the present study, in which Ss with excellent interocular transfer were intermixed with Ss showing rather low level transfer.

The failure of pigmentation to exert an influence on interocular transfer in guinea pigs is quite interesting. Interocular transfer in the albino rat is quite limited, whereas pigmented rats show virtually perfect transfer (Sheridan, 1965). This strain difference has been shown to depend on a reduction, concomitant with albinism, of the optic uncrossed fiber bundles which are sparse in rats (Lund, 1965; Creel \& Sheridan, 1966; Sheridan \& Shrout, 1966). The same reduction with albinism occurs in rabbits (Giolli \& Guthrie, 1969). This suggests that the relationship between albinism and diminished uncrossed fiber system density is somewhat general. Why, 
then, does the reduction fail to influence interocular transfer in guinea pigs whose uncrossed fiber systems are said to be the Jeast dense of ail mammais (Polyak, 1957)?

Two hypotheses, neither of which is clearly adequate, come readily to mind. Perhaps the uncrossed fiber bundles are already so sparse in guinea pigs that any further reduction fails to reveal itself in behavioral consequences. This would be consistent with Polyak's report that $1 \%$ or fewer of the optic fibers fail to decussate in guinea pigs, as well as with the observation made by Creel (1969) that averaged evoked potentials from the uncrossed system are absent at the cortical level in guinea pigs. However, this hypothesis presumably must account for the occurrence of interocular transfer in guinea pigs by attributing it entirely to conduction across commissural pathways. This should mean that guinea pig transfer would be eliminated by forebrain commissurotomy. But Levinson (1970) compared interocular transfer in commissurotomized guinea pigs to that in sham-operated guinea pigs, and, though he observed a reliable reduction in interocular transfer in operated Ss, transfer was still in excess of $50 \%$ on the average.

A second hypothesis is that the uncrossed fiber bundles are heavy in guinea pigs and that any reduction concomitant with albinism has negligible behavioral effects. This hypothesis is consistent with the report of Hess (1958) that fully $25 \%$ of the optic fibers fail to decussate in guinea pigs. However, on this hypothesis, it would be difficult to account for incomplete transfer in guinea pigs. If $5 \%$ of the relatively modest optic input of hooded rats is sufficient to mediate perfect interocular transfer in hooded rats (Sheridan, 1965), it is hard to see how $25 \%$ of the much more dense optic input system found in guinea pigs would fail to do so.

The first hypothesis could be saved in a variety of ways, for example, by postulating transfer of pattern discriminations via lower-leve] across-the-midline pathways. Such transmission has been reported by Sechzer (1964) using cats and by Black \& Myers (1964) using chimpanzees. What is needed, however, is more research, especially anatomical research, to clarify the contradictory statements of Polyak (1957) and Hess (1958) concerning optic uncrossed-fiber density in guinea pigs.

The brightness and pattern discriminations did not differ with respect to rate of acquisition or amount of interocular transfer. This may seem surprising, since previous studies done on other species have usually indicated that the brightness task was more easily acquired and/or transferred than was a pattern task (Meikle \& Sechzer. 1959; Sheridan, 1965; Sheridan \& Shrout, 1905) However, it should be kept in mind that the present brightness task differed from that of almost all previous studies in that the brightness discrimination was controlled for luminous flux by placing a light randomly over the white or the black door on each trial. This certainly had the effect of requiring Ss to use true brightness cues alone and probably made the problem more difficult. True brightness discriminations have more in common with pattern than with luminous flux discriminations (Bauer \& Cooper, 1964).

It was surprising to find that discrimination occurred under conditions of binocular occlusion in pigmented but not in albino guinea pigs. Quite the opposite state of affairs holds for rats (Chorover \& Chase, 1968). The occurrence of peeking should, if anything, aid interocular transfer. Hence, the finding that pigmented guinea pigs exhibit incomplete transfer should hold even more strongly if the present occluders had been perfectly effective. But the basis for discrimination with eyes covered in pigmented guinea pigs is not clear. Albino rats apparently do so by utilizing light cues which pass through the iris (Chorover \& Chase, 1968), but this should certainly occur more readily in albino than in pigmented guinea pigs. It is now known that the occurrence of peeking in albino rats depends upon the size of the occluder relative to the size of the eye (T.J. Hottman, personal communication). Chorover \& Chase (1968) used occluders of a size which must have left a good deal of the orb exposed. Since the occluders were black, incomplete coverage of the eye would be immediately apparent in albino guinea pigs but not in pigmented ones. Thus a systematic bias in the direction of small occluders for pigmented Ss might have occurred in the present study. It is impossible to say whether this hypothesis is correct. In any case, the finding that pigmented guinea pigs can do visual discriminations with both eyes occluded certainly lacks generality, since neither Petre \& Sheridan (1966) nor Levinson (1970) found such peeking.

\section{REFERENCES}

BAUER, J. H., \& COOPER, R. M. Effects of posterior cortical lesions on performance of a brightness discrimination task. Journal of Comparative \& Physiological Psychology. 1964. 58, 84-92.

BLACK, P. \& MYFRS, R. Visual function of the lorebrain commissures in the ehimpanze. Science, 1964, 146. 799-800.

CHOROVER, S. I., \& CHASE. R. Persistence of visual pattern discrimination in binocularly occluded albino rats. Journal of Comparative \& Physiological Psychology, 1968, 65, 238-245.

CREEL, D. J. Ipsi- and contralateral visual evoked potentials in rats, guinea pigs, cats and men. Unpublished doctoral dissertation, University of Utah, 1969.

CREEL, D. J., \& SHERIDAN, C. L. Monocular acquisition and interocular transfer in albino rats with unilateral striate ablations. Psychonomic Science, 1966, 6,89-90.

GELLERMAN, L. W. Chance orders of alternation in visual discrimination experiments. Journal of Genetic Psychology. 1933, 42, 206-208.

GIOLLI, R. A., \& GUTHRIE, M. D. The primary optic projections in the rabbit. An experimental degeneration study. Journal of Comparative Neurology, 1969, 136, 99-126.

HESS, A. Optic centers and pathways after eye removal in fetal guinea pigs. Journal of Comparative Neurology, 1958, 109, 91-115.

LEVINSON, D. M. Monocular acquisition and interocular transfer of two types of discrimination in normal and corpus-callosum-sectioned guinea pigs. Unpublished doctoral dissertation, University of Southern California, 1970.

LEVINSON, D. M., \& SHERIDAN, C. L. Acquisition and retention of monocular discriminations in rats as a function of relevant (reversal) or irrelevant opposite-eye training. Psychonomic Science, 1967, 8, 475-476.

LUND, R. D. Uncrossed visual pathways of hooded and albino rats. Science, 1965, 149, 1506-1508.

MEIKLE, T., \& SECHZER, J. A. Interocular transfer of brightness discrimination in "split-brain" cats. Science, 1960, 132, 734.

PETRE, C. C., \& SHERIDAN, C. L. Interocular transfer in albino and pigmented perinatal guinea pigs. Psychonomic Science, 1966, 6, 215-216.

POLYAK, S. The vertebrate visual system. Chicago: University of Chicago Press, 1957.

SECHZER, I. A. Successful inferocular transfer of pattern discrimination in "split-brain" cats with shock avoidance motivation. Journal of Comparative \& Physiological Psychology, $1964,58,76-83$.

SHERIDAN, C. L. Interocular transfer of brightness and pattern discriminations in normal and corpus callosum-sectioned rats. Journal of Comparative \& Physiological Psychology, 1965, 59, 292-294.

SHERIDAN, C. L., \& SHROUT, L. L. Interocular transfer in the rat: The role of the occlusion process. Psychonomic Science, 1965, 2, 173-174.

SHERIDAN, C. L., \& SHROUT, L. L. Differences in the effectiveness of optic uncrossed fiber systems in albino and hooded rats. Psychonomic Science, 1966, 4, 177.178. THOMPSON, R., \& BRYANT, H. Memory as affected by activity of the relevant receptor. Psychological Reports, 1955, 56, 959-964. 